\title{
HYPOPROTHROMBINAEMIA IN THE NEWBORN
}

BY

\author{
A. S. DOUGLAS and P. DAVIES \\ From the United Oxford Hospitals
}

(RECEIVED FOR PUBLICATION JULY 18, 1955)

In 1935 Quick introduced the one-stage 'prothrombin' test for the quantitative assay of prothrombin (Quick, 1935). It is now realized that a prolonged one-stage clotting time, using this test, can be due to deficiencies not only of prothrombin but also of two other plasma coagulation factors known as Factor V and Factor VII. Factor V was discovered by Owren as the result of investigation of a case of haemorrhagic disease with a prolonged one-stage clotting time, which was not due to a deficiency of prothrombin-the precursor of thrombin (Owren, 1947). The term Factor VII was introduced by Koller, Loeliger and Duckert (1951). Factor VII is important because its deficiency is the main factor which controls the prolonged one-stage 'prothrombin' time resulting from the administration of the coumarin drugs. It was the object of the present investigation to determine factors which control the one-stage clotting time in newborn infants.

\section{Material and Methods}

Collection of Plasma. Venous blood was collected into a graduated centrifuge tube and mixed with $3 \cdot 8 \%$ sodium citrate in the proportion of 9 parts of blood and 1 part of citrate.

Reagents. The reagents-human brain thromboplastin, $M / 40$ calcium chloride, human thrombin, human 'prothrombin', human fibrinogen and aluminium hydroxide $\mathrm{C} \alpha$-were prepared by the methods described by Biggs and Macfarlane (1953).

Methods. Quick's one-stage 'prothrombin' time and related saline dilution curve were described by Biggs and Macfarlane (1953). The percentage is read from the saline dilution curve. The preparation of the thrombinfibrinogen dilution curve is described by Biggs (1951). The two-stage area method of Biggs and Douglas (1953) was used for the measurement of prothrombin.

Estimation of FACTOR V. Factor V was estimated (a) by the activation of 'purified' prothrombin, a modification of the method of McClaughry and Seegers (1950) and is described by Douglas and Biggs (1953); $(b)$ by the ability to correct stored normal oxalated plasma.

When oxalated plasma is stored the Factor $\mathrm{V}$ is labile and the one-stage clotting time lengthens. The ability of infants' plasma to correct this prolonged one-stage clotting time was tested by using $50 \%$ mixtures and compared with the property in this respect of fresh citrated normal plasma.

Estimation OF FACTOR VII. This was estimated by the method described by Biggs and Macfarlane (1953). The principle of this is that 'tromexan' plasma is not usually sufficiently deficient in prothrombin significantly to affect the one-stage clotting time (Douglas, 1955). Mixtures of normal and 'tromexan' plasmas are made, and the one-stage clotting times performed on the mixtures. When these clotting times are plotted against the reciprocal of the concentration of Factor VII, a straight line relationship can be established if allowance is made for the residual Factor VII content of the 'tromexan' plasma. To test the Factor VII content of an infant's plasma 1 in 10 mixtures are made of infantile with 'tromexan' plasma and of normal with 'tromexan' plasma. The one-stage clotting times of the mixtures are then recorded.

Example. The following is a worked example:

Tromexan plasma $\quad . . \quad \ldots=44 \mathrm{sec}$.

1 part normal plasma in 9 parts

'tromexan' plasma .. $\quad . \quad=21 \mathrm{sec}$.

1 part infant plasma in 9 parts

'tromexan' plasma ....$=38 \mathrm{sec}$.

Reading from a graph prepared as described:

$$
\begin{aligned}
& 44 \text { sec. }=3 \% \\
& 21 \text { sec. }=14 \cdot 2 \% \\
& 38 \text { sec. }=3 \cdot 8 \%
\end{aligned}
$$

Therefore the percentage Factor VII in an infant's plasma $=$

$$
\begin{aligned}
& \frac{3 \cdot 8-3}{14 \cdot 2-3} \times 100 \\
= & \frac{0 \cdot 8}{11 \cdot 2} \times 100 \\
= & 7 \% .
\end{aligned}
$$

Estimation of Antithrombin. This method is described by Douglas and Biggs (1953). The area method of prothrombin assay is applicable only when the normal and test specimens have the same antithrombin content. In three observations the curve of thrombin destruction by the infants was similar to the normal.

Healthy infants were examined. Specimens of cord blood were collected shortly after birth into a syringe by 
venepuncture of the umbilical vein. Specimens of blood collected by dripping from the cut end of the cord almost invariably clot, probably due to admixture of tissue thromboplastin from the cord. At $\mathbf{4 8}$ to $\mathbf{7 2}$ hours after birth a further specimen was obtained by venepuncture of the antecubital veins, and on occasion of the external jugulars. It is inevitable that more specimens were collected than could be included in this investigation, many having to be excluded in account of clotting. A specimen of $1.8 \mathrm{ml}$. was collected into $0.2 \mathrm{ml}$. of 3.8 sodium citrate. This gave just sufficient plasma to be able to do Quick's one-stage test, the area two-stage test and the Factor VII content of each specimen. To half of the infants $10 \mathrm{mg}$. 'synkavit' were administered by intramuscular injection at the time of withdrawal of the cord blood.

\section{Results}

Factor V. The Factor V was estimated by the two methods described above.

(a) Four specimens of third-day infant blood were examined. The mean activation of the prothrombin under the influence of Factor $\mathbf{V}$. from these specimens is as good as that of the mean of the normals (Fig. 1).

(b) The correction of stored oxalated plasma is shown in Table 1.
TABLE 1

CORRECTION OF STORED OXALATED PLASMA

\begin{tabular}{c|c|c}
\hline Stored Plasma & $\frac{+\frac{1}{2} \text { Normal Plasma }}{15 \cdot 7 \mathrm{sec} .}$ & $\frac{+\frac{1}{2} \text { Infant Plasma }}{16 \cdot 7 \mathrm{sec} .}$ \\
\hline $21 \cdot 8 \mathrm{sec}$. & (Mean of 7 observations.)
\end{tabular}

Factor VII and Prothrombin. Forty-two infants were examined. To 21 of these $10 \mathrm{mg}$. of vitamin $\mathrm{K}$ were given as described above. The mean of the results is shown in Fig. 2 and Table 2.

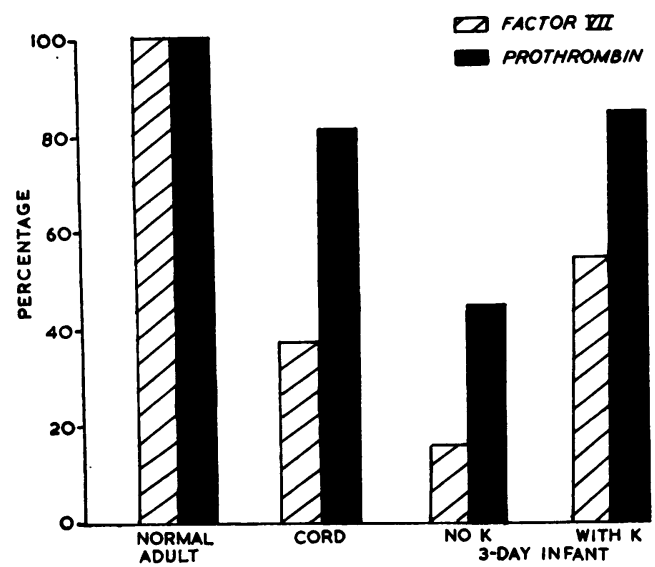

FIG. 2.-This histogram represents the level of Factor VII and prothrombin in the normal adult, and the cord blood (42 observations); also shown are the levels in the infant blood at the third day, when no vitamin $\mathrm{K}$ has been given and, when $10 \mathrm{mg}$. 'synkavit' have been administered intramuscularly shortly after birth.

TABLE 2

MEAN OF RESULTS FOR FACTOR VII AND PROTHROMBIN

\begin{tabular}{l|c|c|c|c}
\hline & Normal & Cord & $\begin{array}{c}\text { 3rd Day } \\
\text { No } \\
\text { Vitamin K }\end{array}$ & $\begin{array}{c}\text { 3rd Day } \\
\text { with } \\
\text { Vitamin K }\end{array}$ \\
\hline $\begin{array}{c}\text { Factor VII } \\
\text { Prothrombin } \\
\begin{array}{c}\text { Quick's one- } \\
\text { stage test }\end{array}\end{array}$ & $100 \%$ & $38 \%$ & $15 \%$ & $54 \%$ \\
\hline
\end{tabular}

There is a reduced level of both Factor VII and prothrombin in the cord blood. These levels fall considerably further at the third day. If vitamin $\mathrm{K}$ is given it fails to produce normal content of these factors on the third day, but it maintains levels at least as good as in the cord blood. In Figs. 3 and 4 the means of the observations on the two-stage test are shown.
Fig. 1.-These curves represent the activation of purified prothrombin by Factor V. The discontinuous lines represent dilutions of normal $(100 \%, 50 \%$, $25 \%$ ). The continuous line represents the findings in the mean of four observations on third-day infant bloods. 


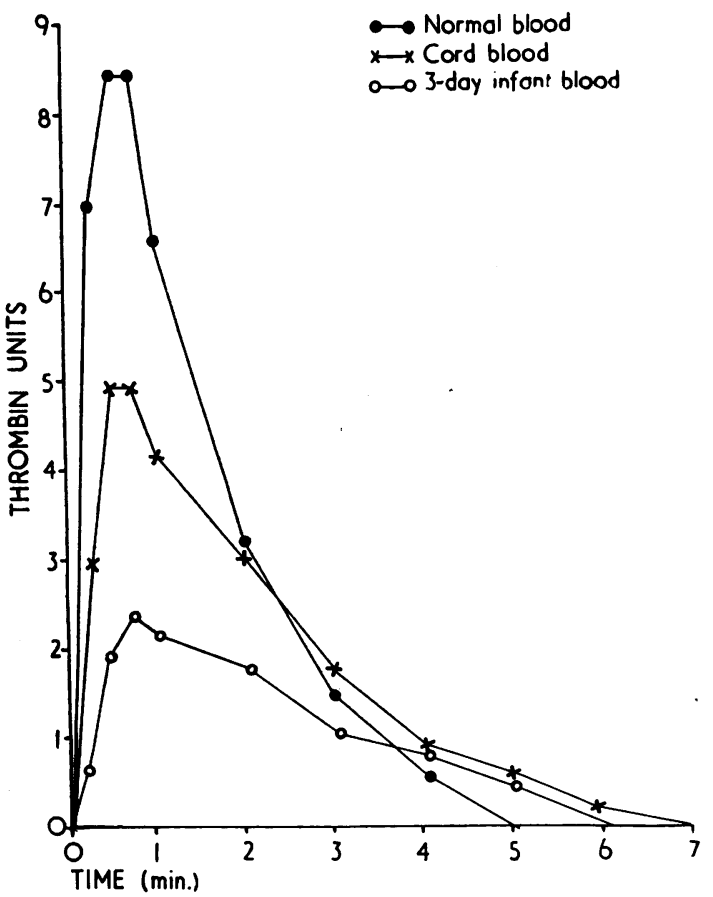

Fig. 3.-These curves represent the results of the two-stage test on the normal, the cord blood, and the third-day infant blood when no vitamin $\mathrm{K}$ has been given. The mean of the observations is represented.

\section{Discussion and Conclusions}

From these results it may be concluded that the 'hypoprothrombinaemia' of the newborn is due to a deficiency of both Factor VII and prothrombin. It is probable that the deficiency in Factor VII is the cause of the prolonged one-stage clotting time, since the degree of prothrombin deficiency observed is not sufficient to be likely to cause lengthening of the one-stage time (Biggs and Douglas, 1953). The degree of deficiency of these factors is much greater on the third day than it is in the cord bloods. The administration of water-soluble vitamin $K$ to the infant prevents the fall in Factor VII and prothrombin, but does not restore these factors to normal levels.

Loeliger and Koller (1952) have also investigated the Factor VII and prothrombin content of cord blood and concluded that both of these factors were deficient. They record much lower figures than were found in this investigation (24\% Factor VII and $28 \%$ prothrombin in a series of 33 cord bloods). The techniques employed by Loeliger and Koller are very different from those used in this investigation.

From the limited number of observations made

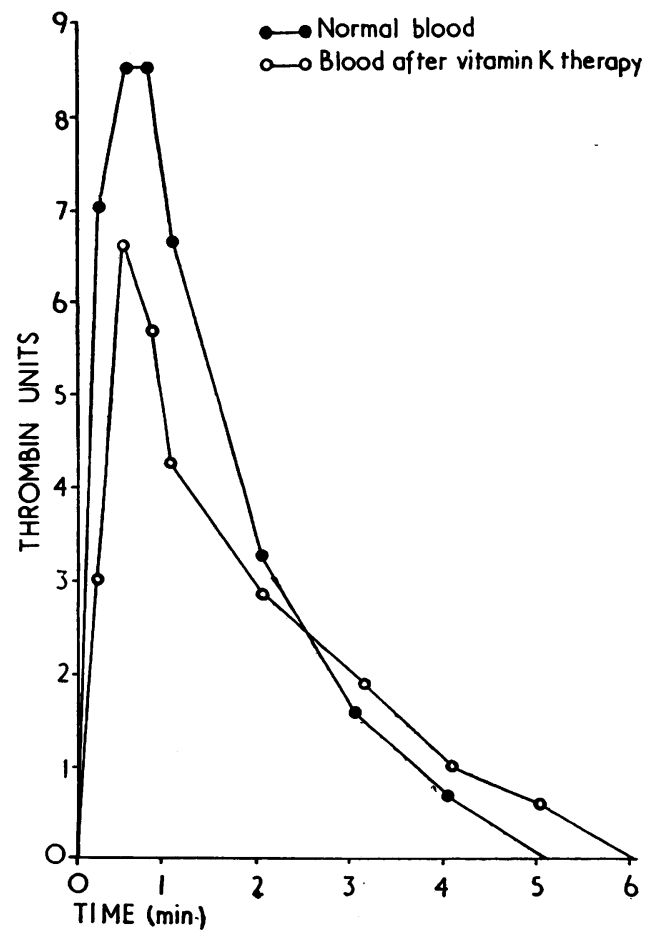

Fig. 4.-These curves represent the results of the twostage test on the normal and the third-day infant blood when vitamin $K$ has been given. The mean of the observations is represented.

in this study it is probable that there is no great deficiency of Factor $\mathrm{V}$ in the newborn. This confirms the findings of Stefanini (1951) who found 'the labile-factor activity only slightly depleted, whereas plasma prothrombin activity was much reduced during the third day after birth'. Stefanini was using a technique involving correction of the prolonged one-stage clotting time of stored oxalated plasma.

There has been some doubt thrown on the value of vitamin $\mathrm{K}$ in the prevention and management of haemorrhagic disease of the newborn. Hay, Hudson and Rodgers (1951) found that vitamin K administered to the mothers did not reduce the incidence of this disease. Sandford, Shmigelsky and Chapin (1942) found that vitamin K administered to the baby, or to the mother before birth, raised the prothrombin level but did not affect the frequency of haemorrhagic manifestations. It was not the object of this investigation to study the complete coagulation mechanism in the newborn nor to establish the relationship of vitamin $\mathrm{K}$ to the incidence and management of haemorrhagic disease of the newborn. It may well be that the coagulation 
defect is more extensive than deficiency of Factor VII and prothrombin. Biggs and Macfarlane (1953) have shown that the thrombin-fibrinogen reaction is abnormal in the newborn. Douglas (1954) has shown that the serum from an infant with haemorrhagic disease of the newborn was defective in its ability to form intrinsic thromboplastin. Haemorrhage in the newborn may be due to abnormalities other than those associated with a prolongation of the one-stage clotting time; for example, thrombocytopenia of the newborn is a well-recognized entity.

This investigation presents reasonable evidence that the administration of vitamin $\mathrm{K}$ to the newborn infant arrests the usual fall in both Factor VII and prothrombin. Even if deficiency of Factor VII and prothrombin proves ultimately to be only a contributory factor in haemorrhagic disease of the newborn, it is of importance to know that vitamin $\mathrm{K}$ does control the level of these substances.

\section{Summary}

The 'hypoprothrombinaemia' of the newborn is due to a deficiency both of Factor VII and prothrombin. Water-soluble vitamin $\mathrm{K}$ given to the infant, though not producing normal levels of these coagulation factors, prevents the deficiency which is normally present on the third day.

We wish to thank Dr. R. G. Macfarlane, Dr. Rosemary Biggs and Dr. V. Smallpeice for their guidance and interest in this investigation. One of us (A.S.D.) wishes to thank the Medical Research Council for a fellowship in clinical research, enabling him to carry out this work.

\section{REFERENCES}

Biggs, R. (1951). Prothrombin Deficiency. Oxford. and Douglas, A. S. (1953). J. clin. Path., 6, is. and Macfarlane, R. G. (1953). Human Blood Coagulation and its Disorders. Oxford.

Douglas, A. S. (1955). Clin. Sci., 14, 601. (1954). Unpublished observations.

and Biggs, R. (1953). Glasg. med. J., 34, 329.

Hay, J. D., Hudson, F. P. and Rodgers, T. S. (1951). Lancet, 1, 423.

Koller, F., Loeliger, A. and Duckert, F. (1951). Acta Haemat,, Basel, 6, 1.

Loeliger, A. and Koller, F. (1952). Ibid., 7, 157.

McClaughry, R. I. and Seegers, W. H. (1950). Blood, 5, 303.

Owren, P. A. (1947). Acta med. scand., Suppl. 194.

Quick, A. J. (1935). J. biol. Chem., 109, Ixxiii.

Sanford, H. N., Shmigelsky, I. and Chapin, J. M. (1942). J. Amer. med. Ass., 118, 697.

Stefanini, M. (1951). Lancet, 1, 606. 